\title{
Kitchen Food Waste Inventory for Residential Areas in Baghdad City
}

\author{
Salam J. Bash Al-Maliky ${ }^{1} \&$ Zainab Qahtan ElKhayat ${ }^{1}$ \\ ${ }^{1}$ AlMustansiriya University, Iraq \\ Correspondence: Salam J. Bash Al-Maliky, AlMustansiriya University, Iraq. E-mail: \\ Salambash2000@yahoo.com; bashs@ohio.edu
}

Received: June 2, $2012 \quad$ Accepted: July 17, $2012 \quad$ Online Published: July 22, 2012

doi:10.5539/mas.v6n8p45

URL: http://dx.doi.org/10.5539/mas.v6n8p45

\begin{abstract}
An inventory and generation rate for the kitchen food waste were determined in residential areas across Baghdad, Iraq as a first step towards more developed and sustainable solid waste management system. The study was based on collecting data from 20 families from 20 different locations across the city for the period from November, 2011 through June, 2012, regarding their total weekly food purchases and wastes in addition to other relevant social information in order to determine statistical prediction formulae for the waste generation rate and food purchase by the application of Multiple Linear Regression analysis MLR, via the software MINITAB 15. The results have shown that the food waste generation in Baghdad, was highly influenced by the number of children family members rather than the adults whom had very low impact on I, while the total food purchase was determined to be almost equally influenced by these two variables. Also the family's monthly income had proven so insignificant impact on both total food purchases and hence the waste generation.
\end{abstract}

Keywords: Baghdad, kitchen food waste, multiple linear regression, waste inventory, waste generation rate

\section{Introduction}

Municipal solid wastes were assumed to comprise organic (food waste, mixed paper, yard wastes) and inorganic materials (plastics/refractory organics, glass, tin cans/aluminum, and other inorganics). Studies have determined that food waste represent significant portions that made it on the third largest portion of waste stream in big nations like the U.S., where, more than 34 million tons of food waste was generated in 2010, more than any other material category but paper, and it was accounted for almost $14 \%$ of the total MSW stream (Morino, 2012). Also, according to the Stockholm International Water Institute SIWI (2012), "In the US, for instance, as much as 30\% of food, worth some USD 48.3 billion, is thrown away", while this percentage was about $17 \%$ in UK for the year 2008 (Department for Environment, Food and Rural Affairs, 2010). Also, it was found that it impacts public health (rots, smells, and attracts rodents) and costs (collection frequency) (Komilis \& Ham, 2004).

For countries like Iraq were no state laws that mandate the recycling of MSW, the realization of the environmental impacts and human health risks related with biodegradable waste as the kitchen food waste, would raise the consideration to the necessity to initiate legislative steps towards such kind of laws in order to roadmap the development of a more sustainable and environmentally sound management of this waste fraction (Al.Ansari, 2012). As the analysis of economics and environmental consequences for household food waste, plays an essential role for the decision makers to plan and prioritize future management schemes, a corner stone for such analysis would be the inventory and generation rate of such kind of waste. A life cycle inventory is used to quantify total materials, energy, costs and environmental flows for food waste management system (collection followed by compost, waste-to-energy or landfill), based on the determination of the most effective variables on that inventory, hence many factors were discussed as effective on the inventory and waste generation for different communities, such as the social, economic and technical ones. Abel (2009) did show that education, income and social status were the important factors influencing per capita solid waste generation in Ogbomoso, Oyo state, Nigeria, while age, location, occupation and amount charged for waste collection were the determinants for Ibadan Metropolis, Oyo state, Nigeria, according to Ajani (2007).

Multiple linear regression analysis MLR were good tool for many researchers to predict the effective variables on the generation of solid waste in general, including food waste. Xiao et al. (2007) had shown that the Gross Domestic Product GDP, per capita income and population were the governing variables (independent variables) for the growth of the total solid waste amount (dependent variable) in Beijing, among which GDP has been 
identified to be the strongest factor, indicating that the environment has been paying the price for the economic growth. Skourides et al. (2008) had used similar analysis to determine that the food waste production in Cyprus was influenced by socio-economic (household size, income and percentage of children) and behavioral factors (feeding food waste to domestic animals and consuming ready food). Also, Yatima and Arshad (2010) had determined that family size and lifestyle factors, particularly the eating habits and dining out activity of resident, contribute significantly to variations in the generation of residential waste in Malaysia.

Another main aspect for food waste inventory and generation rate prediction is to be used as an input in waste management pricing in the sense of calculating the required costs for each of its processes and the expected revenue for its final products; e.g. compost and energy. An inventory model was employed to compare the options of recycling or disposal of used products, this model did not address the issues of secondary materials storage and prices, but it demonstrated the concept of inventory as a way to influence the cost of waste management options (Garrick \& Shih, 2007).

The goal of this study was to develop an inventory of the kitchen food waste, its generation rate, and the main factors that affect it in Baghdad, towards the determination of statistical models for the relations between the relevant variables as a first step towards planning the proper solid waste management and handling scheme.

\section{Materials and Methods}

The study was based on sampling the family's weekly kitchen food waste, in grams, from different families resided at different locations and complexes across Baghdad city. These families were selected on the base of incorporating various numbers of family members and levels of income in order to involve as much effective variables as possible. Ten families were selected, on voluntarily bases, from each side of Baghdad city; Rasafa and Karkh, which make the total of twenty families, the selection of which was meant to cover a comprehensive area of the city, as shown in Figure 1. The family's weekly food purchases in grams, excluding all kinds of meat, and their leftovers (waste) were weighted, using digital kitchen type scales, on weekly bases (gram per family per week), for the months November 2011 through June 2012. In addition, each family was asked to fill information regarding number Adults, and children (under 18 years old) members, and the cash amount for their purchases in Iraqi Dinar ID.

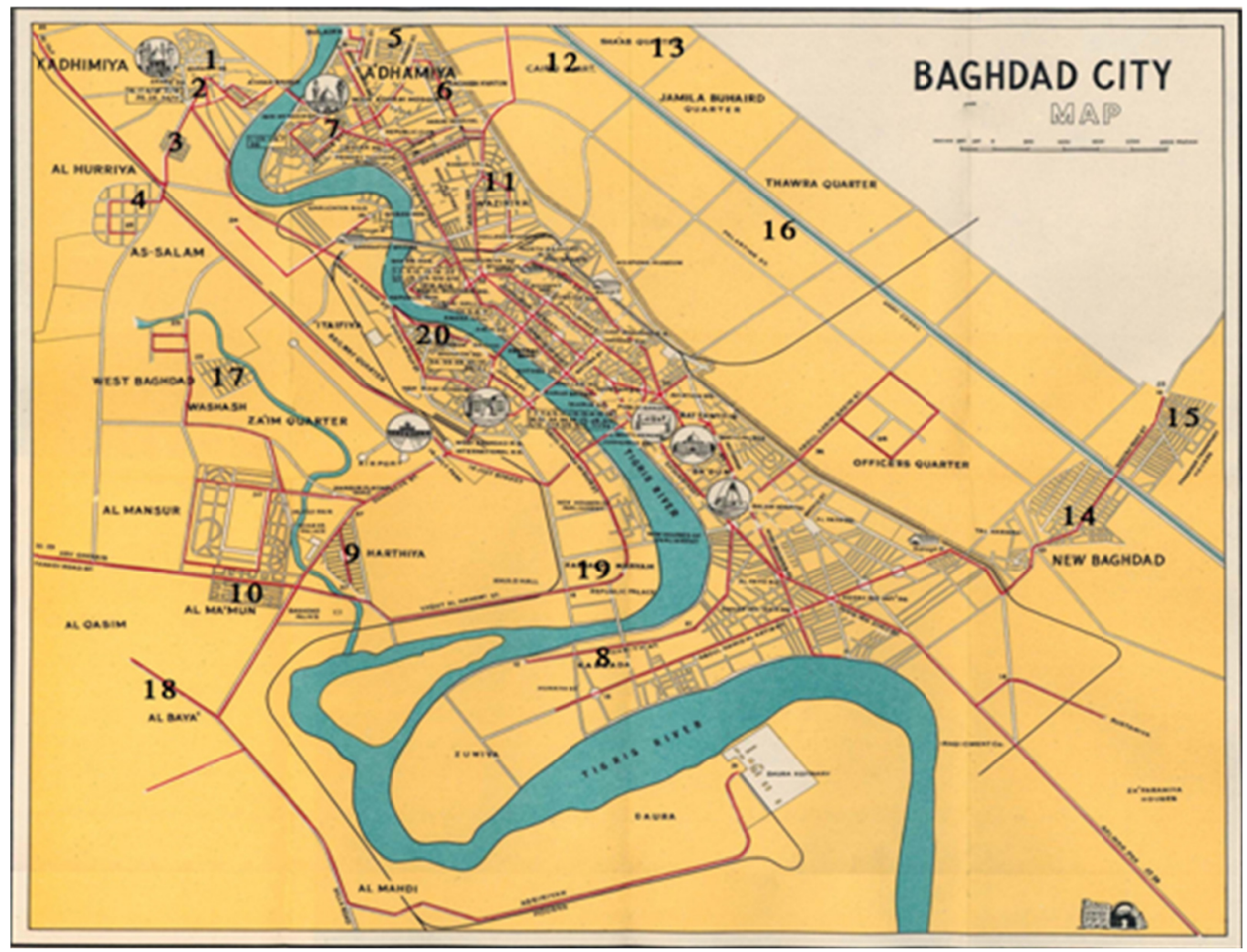

Figure 1. Baghdad city map showing the denoted residential areas understudy 
Statistical analysis of the collected data had started with averaging these values in order to have representative variables for each family against its weekly food purchases and leftovers. Kolmogorov Smirnov test (K-S test) was used to determine the normality of collected data in order to make sure that they were normally distributed. Pearson's coefficient of correlation (r), was determined in order to investigate the possible correlations between the various sets of data, and once these sets had shown sound correlation possibilities, the MLR analysis via the MINITAB 15 software was used to determine statistical models that might be used to predict the weekly food waste amount and weekly food purchases (dependent variable) as a function of other variables (independent variables) for Baghdad city. MLR attempts to model the relationship between two or more explanatory variables and a response variable by fitting a linear equation to observed data. Every value of the independent variable $\mathrm{x}$ is associated with a value of the dependent variabley (Chan, 2004).

\section{Results and Discussions}

The collected data all over the period of study for the 20 families were averaged and tabulated as shown in Table 1. The results of K-S normality tests have shown that the data concerning families weekly food waste generation, weekly food purchase and monthly income were normally distributed as illustrated by Figure 2 to Figure 4, respectively. Some direct indications might be exerted from table1, as follows:

1) The bigger the family size, the bigger the weekly food purchase, which is rational and refers to another indication that the majority of Baghdad families rely on household food.

2) In average, around $28 \%$ of the weekly food purchase was wasted every week, which lies in the norm of international practices; e.g. USA and UK that were mentioned earlier.

3) The less the children in a family, the less the percent of food waste, even though the total number of family members was the same. As an example, for the family number 2, the percent waste was 18.33 while it was 29.34 and 22.87 for families 4 and 17 respectively.

4) The family's monthly income had no significant impact on the weekly food purchase nor the food waste amount. This was another indicator that both food purchase and food waste were strictly linked to the social traditions and habits of Baghdad families rather than the economic status.

Table 1. Data collected from different locations across Baghdad city

\begin{tabular}{|c|c|c|c|c|c|c|}
\hline \multirow[t]{2}{*}{ Location } & \multicolumn{2}{|c|}{ Residents } & \multirow{2}{*}{$\begin{array}{l}\text { Monthly income } \\
\text { Iraqi Dinar }\end{array}$} & \multirow{2}{*}{$\begin{array}{c}\text { Total amount } \\
\text { gram }\end{array}$} & \multirow{2}{*}{$\begin{array}{c}\text { Weekly waste } \\
\text { gram }\end{array}$} & \multirow{2}{*}{$\begin{array}{c}\text { Waste percentage } \\
\% \\
\end{array}$} \\
\hline & Adults & children & & & & \\
\hline 1 & 2 & 2 & 2000000 & 17100 & 4820 & 28.19 \\
\hline 2 & 3 & 0 & 1600000 & 10200 & 1870 & 18.33 \\
\hline 3 & 2 & 3 & 1450000 & 12245 & 3640 & 29.73 \\
\hline 4 & 1 & 2 & 1850000 & 9736 & 2857 & 29.34 \\
\hline 5 & 5 & 1 & 3500000 & 14760 & 4000 & 27.1 \\
\hline 6 & 5 & 3 & 3650000 & 22309 & 7210 & 32.32 \\
\hline 7 & 4 & 0 & 3200000 & 21600 & 3201 & 14.82 \\
\hline 8 & 2 & 0 & 3250000 & 3675 & 823 & 22.39 \\
\hline 9 & 2 & 2 & 1450000 & 16210 & 4690 & 28.93 \\
\hline 10 & 3 & 3 & 1500000 & 18980 & 5890 & 31.03 \\
\hline 11 & 2 & 5 & 1890000 & 23450 & 9210 & 39.28 \\
\hline 12 & 5 & 2 & 4200200 & 24224 & 6211 & 25.64 \\
\hline 13 & 5 & 1 & 2130000 & 24110 & 5300 & 21.98 \\
\hline 14 & 2 & 4 & 3250000 & 21390 & 8150 & 38.1 \\
\hline 15 & 4 & 3 & 3250000 & 23400 & 7390 & 31.58 \\
\hline 16 & 3 & 3 & 1100000 & 23100 & 7420 & 32.12 \\
\hline 17 & 2 & 1 & 3650000 & 10230 & 2340 & 22.87 \\
\hline 18 & 3 & 3 & 2650000 & 22100 & 7340 & 33.21 \\
\hline 19 & 2 & 4 & 2650000 & 21200 & 8430 & 39.76 \\
\hline 20 & 4 & 2 & 2350000 & 23500 & 4000 & 17.02 \\
\hline Average & 3 & 2.2 & 2528510 & 18175.95 & 5239.6 & 28.19 \\
\hline $\begin{array}{l}\text { Standard } \\
\text { Deviation }\end{array}$ & & & 915392.5 & 6086.86 & 2442.27 & 7.05 \\
\hline
\end{tabular}




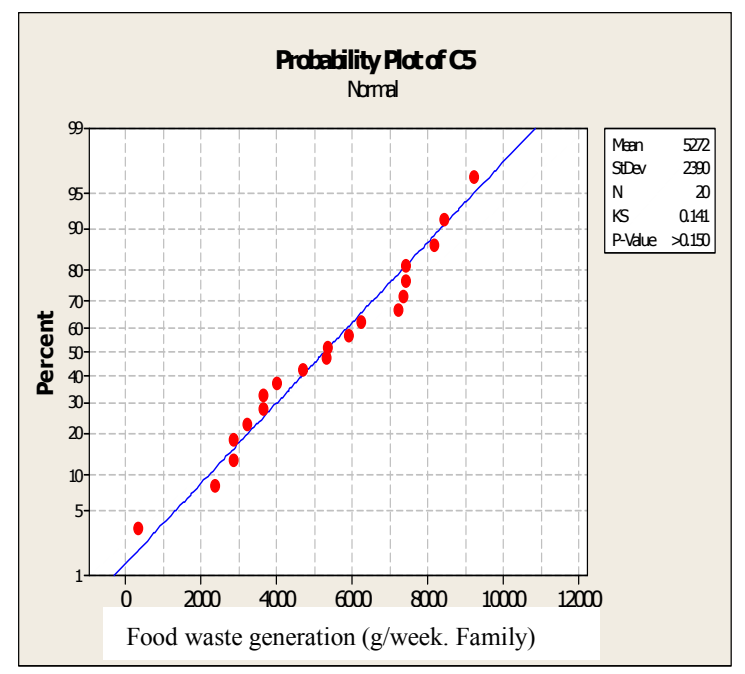

Figure 2. Normal distribution test for food waste generation for families under study

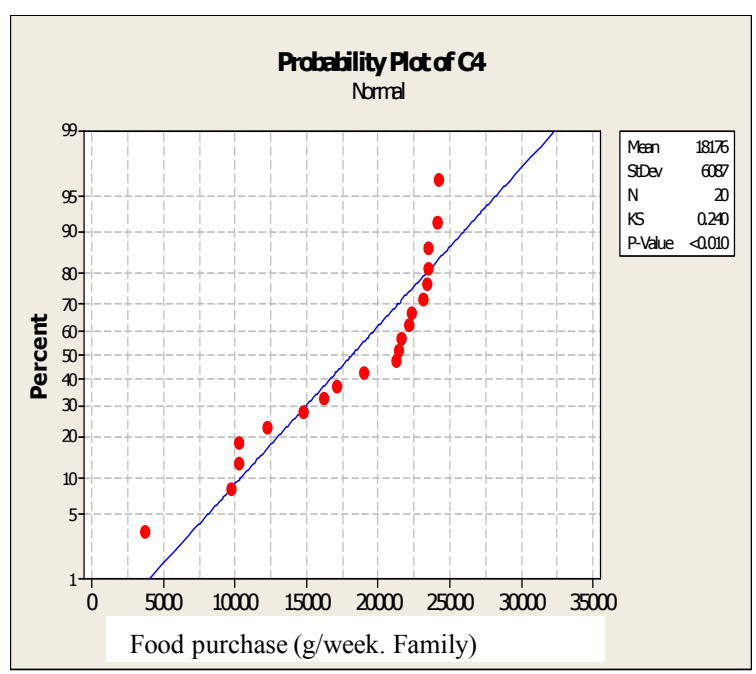

Figure 3. Normal distribution test for food purchases of families under study

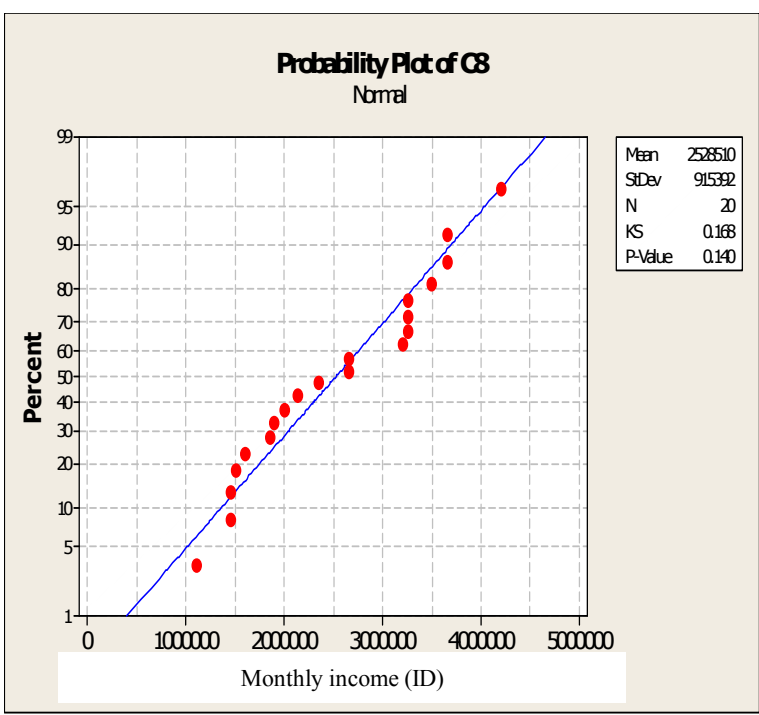

Figure 4. Normal distribution test for monthly income of families under study 


\subsection{Statistical Correlation Test}

Statistical relationships between various sets of data were tested via the determination Pearson's coefficients of correlation as tabulated in Table 2. The weekly purchased food was determined to be almost equally dependent on the number of adults and children numbers in each family ( $\mathrm{r}=0.516$ and 0.525 respectively), or in other words, it did not matter whether the family members were adults or children. This may be attributed to the purchase habits of regular Iraqi families that tend purchase more than the regular needs in order to be ready for unexpected emergencies such as unplanned visits or changes in market status due to the unstable security status. From the other side, it was determined that amount of food waste was highly related to the number of children $(\mathrm{r}=0.870)$, then came the weekly food purchase $(\mathrm{r}=0.798)$, and much less on the number of adult members of each family $(\mathrm{r}=0.121)$. The justification for that effect of children on the waste generation rate may be linked to their psychological structure that tends to try different types and amounts of food for almost non reasonable causes. Finally, it was determined that the correlation coefficients between family's monthly income and other parameters were insignificantly low, which supported the above indication that the monthly income seemed has no significance on the waste inventory or waste generation for Baghdad families.

Table 2. Person's correlation coefficient between variable sets under study

\begin{tabular}{lllll}
\hline Variable & Monthly income & Total amount & Number of adults & Number of children \\
\hline Waste amount & 0.006 & 0.798 & 0.121 & 0.870 \\
Waste percentage & -0.109 & 0.285 & -0.343 & 0.895 \\
Total amount & 0.08 & --- & 0.516 & 0.525 \\
\hline
\end{tabular}

\subsection{Multiple Linear Regression Analysis}

The promising correlation coefficients between the waste amount from one side and each of the three parameters; numbers of adults and children per family and the weekly food purchase from the other side, had paved the way to the use of MLR analysis, in order to determine a statistical model that relates the weekly waste generation rate as a dependent variable, as a function of the independent variables; number of adults per family, number of children per family, and weekly food purchase. Similarly, a statistical model could have been made to relate the weekly food purchase as the dependent variable, to the independent variables; number of adults per family, number of children per family. Table 3 shows the resulted statistical models altogether with the related MLR analysis details.

Table 3. Outcome of MINITAB 15 for the multiple linear regression analysis

\begin{tabular}{|c|c|c|c|c|}
\hline \multicolumn{5}{|c|}{$\begin{array}{l}\text { FW: Food waste (g/week. Family), NA: Number of adults, NC: Number of children, FP: Food Purchase (g/week } \\
\text { Family) }\end{array}$} \\
\hline Predictor & Coef & SE Coef & $\mathrm{T}$ & $\mathrm{P}$ \\
\hline Constant & -972.2 & 408.2 & -2.38 & 0.030 \\
\hline Number of adults $\mathrm{C} 2$ & 106.8 & 152.6 & 0.70 & 0.494 \\
\hline Number of children $\mathrm{C} 3$ & 1108.5 & 140.1 & 7.91 & 0.000 \\
\hline Amount of food purchase (gram) C4 & 0.19137 & 0.03647 & 5.25 & 0.000 \\
\hline $\mathrm{R}-\mathrm{Sq}=96.2 \%$ & $\mathrm{R}-\mathrm{Sq}(\mathrm{a}$ & $5.5 \%$ & & \\
\hline \multicolumn{5}{|c|}{$\begin{array}{l}\text { The regression equation for } \mathrm{C} 4 \text { versus } \mathrm{C} 2, \mathrm{C} 3 \\
\mathrm{FP}=1646+3256 \mathrm{NA}+3000 \mathrm{NC}\end{array}$} \\
\hline Predictor & Coef & SE Coef & $\mathrm{T}$ & $\mathrm{P}$ \\
\hline Constant & 1646 & 2685 & 0.61 & 0.548 \\
\hline Number of adults $\mathrm{C} 2$ & 3255.6 & 637.4 & 5.11 & 0.000 \\
\hline Number of children $\mathrm{C} 3$ & 3000.2 & 581.4 & 5.16 & 0.000 \\
\hline
\end{tabular}


The MINITAB 15 output provides a great deal of information. Under the equation for the regression line, the output provides the least-squares estimates for each parameter, listed in the "Coef" column next to the variable to which it corresponds. The calculated standard deviations are provided in the second column. The third column "T" of the MINITAB 15 output provides test statistics. The "P" column of the MINITAB 15 output provides the P-value associated with the two-sided test. Since the P-values for all three independent variables that influence the prediction of the weekly food waste generation, were highly significant, all variables might be included in the model. In addition, the squared multiple correlation $\mathrm{R}^{2}$ was equal to $95.5 \%$ and the residuals indicated no unusual patterns. These indications had suggested that the inclusion of all three variables explains $96.2 \%$ of the variability of the data. Similarly, the two independent variables shown in table for the prediction of the weekly food purchase were determined to have $\mathrm{R}^{2}$ of $68.0 \%$ that was still suggesting the inclusion of these two variables in the model to explain $71.4 \%$ of the variety of data.

The predicted results were tested for normality via the K-S test as shown in Figure 5 for the food waste generation and Figure 6 for the food purchases. Both of these tested variables were determined to be normally distributed.

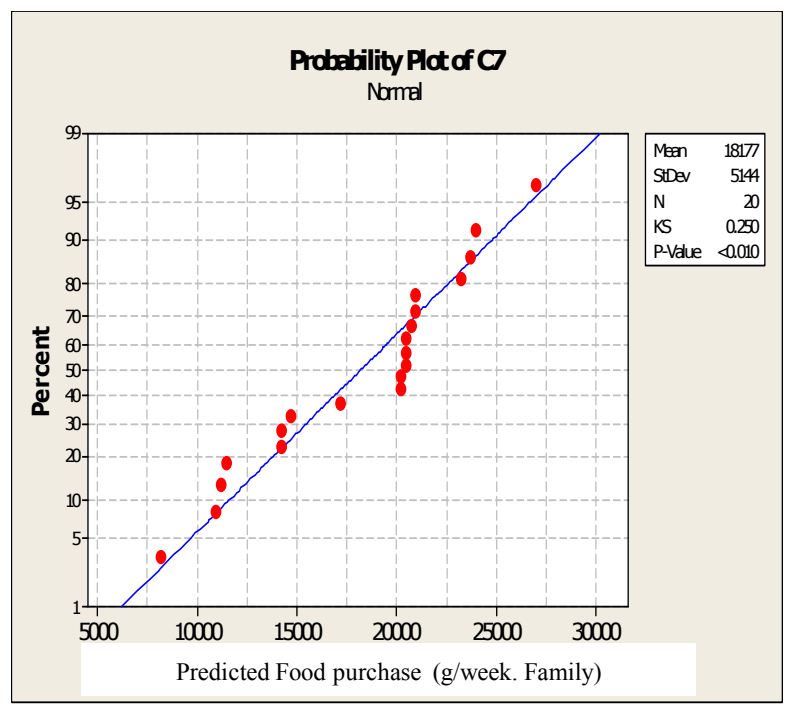

Figure 5. Normal distribution test for the outcome of food waste generation model

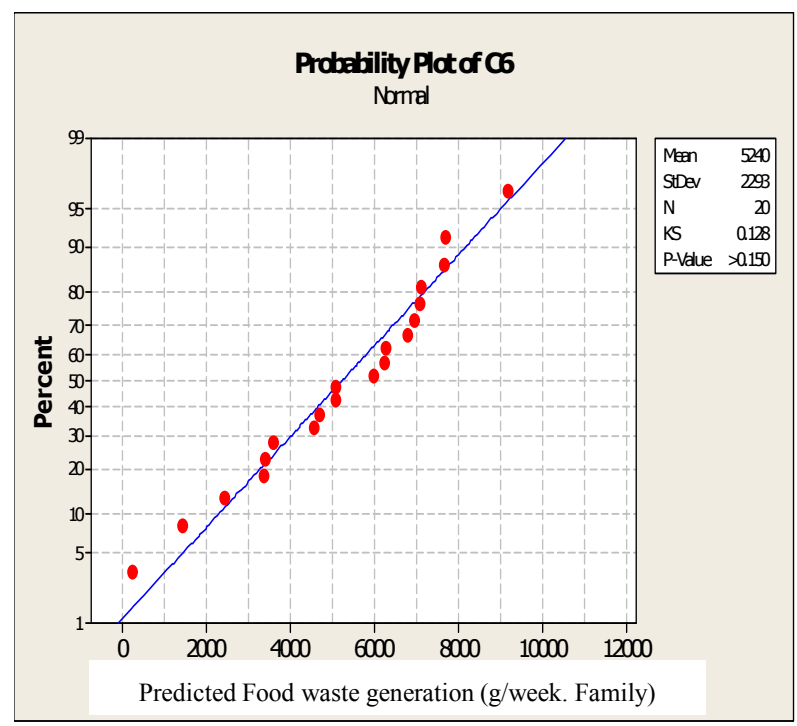

Figure 6. Normal distribution test for the outcome of food purchase model 


\section{Conclusions}

The kitchen food waste was considered as one of the basic constituents of MSW for the various communities, hence it was crucial to determine an inventory and waste generation for the decision makers to design the proper waste management system based on the resulted statistical models that will enable the prediction of future size of waste. In addition, the statistical models would make it clear the most effective variables on the production of food wastes, hence they would lead to the adoption of proper policies and procedures; social or technical, in order to control their size. For the residential areas across Baghdad city, about eight months study was made to determine the most significant variables that affect the generation rate and amount of kitchen food waste. Data regarding food purchases, food wastes in addition to other economic and social data were statistically analyzed, including, but not limited to, correlation test and MLR analysis, and it was resulted that the number of children members of each family had the most effective role on the determination of food waste amount, then came the total food purchase and the least role was for the number of adult members. From another side, it was determined that the total purchased food amount was almost equally affected by the ages of family members (adults or children). An important result of this study was that the monthly family income had no significance on both the total purchases of food and the waste generation for families of Baghdad during the period of study.

\section{References}

Abel, O. A. (2009). An analysis of solid waste generation in a traditional African city: the example of Ogbomoso, Nigeria. Environment and Urbanization, SAGE Journals, 19(2), 527- 537.

Ajani, O. I. Y. (2007). Determinants of an effective solid waste management in Ibadan Metropolis, Oyo state, Nigeria. Journal of Food, Agriculture and Environment, 6(1), 152-157.

Al.Ansari, M. S. (2012). Improving Solid Waste Management in Gulf Co-operation Council States: Developing Integrated Plans to Achieve Reduction in Greenhouse Gases. Modern Applied Science, 6(2), 60-68. http://dx.doi.org/10.5539/mas.v6n2p60

Chan, Y. H. (2004). Biostatistics 201: Linear Regression Analysis. Singapore Medical Journal, $45(2), 55$.

Department for Environment, Food and Rural Affairs. (2010). Retrieved from http:/www.defra.gov.uk/statistics/files/defra-stats-foodfarm-food-foodwastepurchases-100727.pdf

Garrick, L., \& Shih, J. S. (2007). A flexible inventory model for municipal solid waste recycling. Socio-Economic Planning Science, 41(1).

Skourides, I., Smith, S. R., \& Loizides, M. (2008). Sources and factors controlling the disposal of biodegradable municipal solid waste in urban and rural areas of Cyprus. Waste Management Research, 26(2), 188-195. http://dx.doi.org/10.1177/0734242X07085756

Komilis, D. P., \& Ham, R. K. (2004). Life-Cycle Inventory of Municipal Solid Waste and Yard Waste Windrow Composting in the United States. Journal of environmental engineering. http://dx.doi.org/10.1061/(ASCE)0733-9372(2004)130:11(1390)

Moreno Laura, (2012). Turning food waste to energy. United States Environmenal Protection Agency EPA Pacific southwest region.

$\begin{array}{llllll}\text { Stockholm International } & \text { Water } & \text { Institute } & \text { SIWI. } & \text { (2012). } & \text { Retrieved from }\end{array}$ http://www.siwi.org/sa/node.asp? node=343

Xiao, Y., Bai, X. M., Ou, Y., Zhi, Y., Zheng, H., \& Xing, F. F. (2007). The composition, trend and impact of urban solid waste in Beijing. Environ Monit Assess. http://dx.doi.org/10.1007/s10661-007-9708-0

Yatima, S. R. M., \& Arshad, M. A. (2010). Household Solid Waste Characteristics and Management in Low Cost Apartment in Petaling Jaya, Selangor. Health and the Environment Journal, 1(2). 